\title{
PELATIHAN PENGGUNAAN MICROSOFT OFFICE EXCEL DALAM PENATAAN ADMINISTRASI DESA BAGI OPERATOR/SEKRETARIS DESA SE KECAMATAN KEDONDONG KABUPATEN PESAWARAN
}

\author{
Netti Herawati ${ }^{1}$, Subian Saidi ${ }^{1}$, Khoirin Nisa, M.Si. ${ }^{1}$, Drs. Eri Setiawan, M.Si. ${ }^{1}$ \\ ${ }^{1}$ Program Studi Matematika/FMIPA, Universitas Lampung,
}

Penulis Korespodensi: netti.herawati@fmipa.unila.ac.id

\begin{abstract}
Abstrak
Kegiatan penataan administrsi desa meruapakan salah satu hal yang penting dalam pelaksanaan administrasi desa. Selama ini proses pengadministrasian masih berjalan secara manual (melalui alat tulis). Kondisi tersebut mengakiabtkan pencarian arsip sulit dan tak jarang memakan waktu yang lama bahkan bisa berjam-jam. Dengan jumlah penduduk yang relative banyak, pemerintah desa distuntut untuk melaksanakan tugas kearsipan dengan cepat dan rapi. Pekerjaan itu sangat dapat dibantu dengan teknologi saat ini (laptop) melalui software Microsoft office excel. Undang-Undang Nomor 32 Tahun 2004 tentang Pemerintahan Daerah, telah membawa perubahan yang mendasar dalam sistem dan struktur Pemerintahan Daerah serta membawa dampak yang sangat luas bagi penyelenggaraan pemerintahan, perencanaan pembangunan, pengelolaan keuangan dan sistem penganggaran dalam menunjang penyelenggaraan pemerintahan di Daerah, khususnya pada tingkat Pemerintahan Desa. Untuk meningkatkan manajemen Pemerintahan Desa perlu dilakukan penataan administrasi agar lebih effektif dan effisien, penataan administrasi merupakan pencatatan data dan informasi dalam mendukung penyelenggaraan Pemerintahan Desa, maka perlu dilakukan langkah penyempurnaan terhadap pelaksanaan administrasi. Metode yang digunakan adalah metode ceramah, praktek langsung dengan file yang sudah diprogram tinggal diisi, tanya jawab, diskusi dan latihan untuk mengisi form yang sudah diprogram tinggal pengisian. Sehingga setelah adanya kegiatan pelatihan ini diharapkan operator/sekertaris desa dapat melakukan penataan administrasi lebih baik lagi.
\end{abstract}

Kata kunci: Microsoft Office Excel, Administrasi

\begin{abstract}
Village administration structuring activities are one of the important things in the implementation of village administration. So far, the administrative process is still running manually (via stationery). This condition makes searching for archives difficult and often takes a long time or even hours. With a relatively large population, the village government is required to carry out archiving tasks quickly and neatly. The work can be greatly assisted by current technology (laptops) through Microsoft office excel software. Law Number 32 of 2004 concerning Regional Government has brought about fundamental changes in the system and structure of Regional Government and has had a very broad impact on governance, development planning, financial management and budgeting systems in supporting the administration of regional government, especially at the regional level. Village Administration. To improve the management of the Village Government, it is necessary to arrange the administration to be more effective and efficient, the administrative arrangement is the recording of data and information in supporting the implementation of the Village Government, it is necessary to take steps to improve the implementation of the administration. The method used is the lecture method, direct practice with programmed files, just fill in, question and answer, discussions and exercises to fill out the programmed form, just fill it out. So that after this training activity, it is hoped that the village operator/secretary can make better administrative arrangements.
\end{abstract}

Keywords: Microsoft office excel, administration, 
Dipublikasikan

Badan Pelaksana Kuliah Kerja Nyata

Universitas Lampung

Sekretariat Badan Pelaksana Kuliah Kerja Nyata, Universitas Lampung,

J. Prof. Dr. Soemantri Brojonegoro No. 1, Bandar Lampung 35145.

\section{Pendahuluan}

Menurut Badan Pusat Statistik Kabupaten Pesawaran (2020) , bahwa Kecamatan Kedondong Kabupaten Pesawaran memiliki luas 73,37 $\mathrm{Km}^{2}$ yang terdiri dari 12 Keluruhan/Desa yaitu Sukamaju $\left(7,36 \mathrm{Km}^{2}\right)$, Waykepayang $\left(8,27 \mathrm{Km}^{2}\right)$, Kedondong $\left(8,53 \mathrm{Km}^{2}\right)$, Sinar Harapan $\left(4,39 \mathrm{Km}^{2}\right)$, Tempel Rejo $\left(8,9 \mathrm{Km}^{2}\right)$, Pasar Baru (3,46 Km$\left.{ }^{2}\right)$, Kerta Sena $\left(4,45 \mathrm{Km}^{2}\right)$, Gunung Sugih $\left(6 \mathrm{Km}^{2}\right)$, Babakan Loa $\left(5,35 \mathrm{Km}^{2}\right)$, Pesawaran $\left(7,26 \mathrm{Km}^{2}\right)$, Teba Jawa $\left(6,2 \mathrm{Km}^{2}\right)$, dan Harapan Jaya $\left(3,2 \mathrm{Km}^{2}\right)$. Kecamatan Kedondong memiliki jumlah penduduk 34.573 jiwa yang terbagi kedalam 12 Kelurahan/Desa yaitu Sukamaju (2.363 jiwa), Waykepayang (1.519 jiwa), Kedondong (4.828 jiwa), Sinar Harapan (4.125 jiwa), Tempel Rejo (4.390 jiwa), Pasar Baru (3.390 jiwa), Kerta Sena (1.685 jiwa), Gunung Sugih (3.326 jiwa), Babakan Loa (2.220 jiwa), Pesawaran (3.356 jiwa), Teba Jawa (1.252 jiwa), dan Harapan Jaya (1.279 jiwa)..

Perkembangan teknologi informasi dan komunikasi khususnya untuk keperluan administrasi sangat memperngaruhi kebutuhan hidup manusia, salah satunya kebutuhan informasi adalah bagaimana mengakses administrasi pemerintahan Administrasi adalah usaha dan kegiatan yang berkenaan dengan penyelenggaraan kebijaksanaan untuk mencapai tujuan. Jenis Administrasi meliputi: Administrasi Umum; Administrasi Penduduk; Administrasi Keuangan; Administrasi Pembangunan; Administrasi Badan Permusyawaratan Desa (BPD) dan Administrasi lainnya.

Menurut Widjaja (2002) menyatakan Administrasi sebagai perbuatan penyelanggaraan dalam setiap usaha kerja sama sekelompok manusia untuk mencapai tujuan tertentu. Menurut Liang Gie, 1997 (dalam Syafiie, 2003) Administrasi adalah segenap rangkayan penataan terhadap perkerjaan pokok yang dilakukan oleh sekelompok orang dalam kerjasama mencapai tujuan tertentu. Administrasi sangat penting bagi manusia guna mendukung setiap kegiatan yang dilakukan dalam kerja sama mencapai tujuan tertentu. Administrasi sangat penting bagi manusia yang mendukung setiap kegiatan yang di lakukan dalam hubungannya dengan lingkungan sosialnya.

Menurut Strong dalam Syafiie (2002), Pemerintahan dalam yang arti luas memiliki wewenang untuk memelihara kedamaian dan keamanan negara baik ke dalam maupun ke luar. Menurut Undang-Undang Republik Indonesia Nomor 6 Tahun 2014 Tentang Desa. Desa adalah desa dan desa adat atau yang disebut dengan nama lain, selanjutnya disebut Desa adalah kesatuan masyarakat hukum yang memiliki batas wilayah yang berwenang untuk mengatur dan mengurus urusan pemerintahan, kepentingan masyarakat, hak asal usul, dan/atau hak tradisonal yang diakui dan dihormati dalam sistem pemerintahan Negara Kesatuan Republik Indonesia.

Menurut Kurniawan (2005) pelayanan publik merupakan pemberian pelayanan atau melayani keperluan orang lain atau masyarakat yang mempunyai kepentingan pada organisasi itu sesuai dengan aturan pokok tata dan tata cara yang telah ditetapkan. Selanjutnya menurut Moenir dalam Pasolong (2007), mengatakan bahwa Pelayanan adalah proses pemenuhan kebutuhan melalui aktivitas orang lain secara langsung. Sedangkan Sampara dalam Sinambela (2006) berpendapat bahwa Pelayanan adalah suatu kegiatan atau urusan kegiatan yang terjadi dalam interaksi secara langsung antar seseorang dengan orang lain atau mesin secara fisik, dan dapat menyediakan kepuasan pada pelanggan.

Menurut Widjaya dalam Hariyono (2007), Masyarakat adalah sekelompok orang yang mempunyai identitas tertentu, dapat dibedakan dengan kelompok lain dan hidup diam dalam wilayah atau daerah tertentu secara tersendiri. Kelompok ini baik secara sempit maupun luas mempunyai perasaan akan adanya persatuan diantara anggota kelompok dan menganggap dirinya berbeda dengan kelompok lain. Mereka memiliki norma, kententuan dan peraturan yang dipatuhi bersama sebagai suatu ikatan. Perangkat dan peranata tersebut dijadikan pedoman untuk memenuhi kebutuhan kelompok dalam arti seluas-luasnya. 


\section{Jurnal Pengabdian Kepada Masyarakat BUGUH}

Dipublikasikan

Badan Pelaksana Kuliah Kerja Nyata

Universitas Lampung

Sekretariat Badan Pelaksana Kuliah Kerja Nyata, Universitas Lampung, J. Prof. Dr. Soemantri Brojonegoro No. 1, Bandar Lampung 35145.

Menurut PERKA ANRI no. 50 Tahun 2015 Tentang Petunjuk Teknis Pemberkasan Arsip Aktif yang dikutip oleh Anggorowati dkk, 2016, kegiatan mengarsipkan administrasi merupakan salah satu hal penting dalam pelaksanaan administrasi pada suatu institusi atau dalam hal ini pada suatu kecamatan. Kearsipan di kecamatan Kedondong masih belum tertata sesuai dengan standar kearsipan. Arsip disimpan dengan cara ditumpuk didalam filling cabinet, bukan menggunakan folder (map gantung) bahkan terkadang tercampur dengan barang-barang lain sehingga akan sulit untuk menemukan kembali arsip apabila dibutuhkan. Pedoman atau instrument untuk penataan arsip hanya menggunakan Kode Klasifikasi tanpa menggunakan JRA (Jadwal Retensi Arsip). Kondisi tersebut mengakibatkan pencarian arsip sulit dan cukup banyak memakan waktu yang bahkan dapat berjam-jam, padahal standarnya hanya kurang dari 5 menit.

Dengan jumlah penduduk yang relatif banyak pemerintah desa dituntut untuk melaksanakan tugas kearsipan dengan cepat dan rapi. Pekerjaan kearsipan sangat berpengaruh terhadap proses administrasi yang pada akhirnya bermuara pada pelayanan kepada masyarakat/publik. Kegiatan Pengabdian Masyarakat ini mempunyai tujuan selain untuk mengetahui bagaimana penggunaan Microsoft office excel untuk administrasi di pemerintahan desa juga akan memberikan arahan kepada apparat desa tentang pengelolaan arsip yang baik sehingga arsip dan dokumen-dokumen penting yang ada di Desa dapat dikelola untuk kelancaran dan tertib administrasi yang juga mendukung pelayanan administrasi kepada masyarakat untuk menjadi lebih baik. Permasalahan pengelolaan arsip di Kecamatan Kedondong adalah : kehilangan arsip - arsip penting seperti data wilayah, bukti kepemilikan (asset) dll, kecepatan menemukan arsip yang diperlukan membutuhkan waktu relatif lama, berjam-jam bahkan berhari-hari, arsip aktif dan inaktif tercampur sehingga ketika dibutuhkan sulit ditemukan.

Menurut Higau (2015), Melalui pelaksanaan administrasi pemerintahan desa yang baik diharapkan pemerintah desa mampu untuk menyelanggarakan pemerintahan secara baik, agar upaya pemarataan pembangunan dan pelayanan prima kepada masyarakat dapat terlaksana secara optimal.

Undang-Undang Nomor 6 Tahun 2014 tentang Desa, menyebutkan bahwa salah satu kewajiban pemerintah desa adalah menyelenggarakan tertib administrasi desa yang mampu berfungsi sebagai sumber data dan informasi dalam penyelenggaraan pemerintahan Desa, pelaksanaan pembangunan, pembinaan kemasyarakatan dan pemberdayaan masyarakat."Pemerintahan desa yang baik dan bersih (good governance dan clean governance) harus selalu melekat dalam penyelenggaraan pemerintahan Desa, baik dalam pelaksanaan tugas, fungsi, kewenangan, hak, dan kewajiban yang dimiliki oleh pemerintahan Desa". Undang-Undang Nomor 32 Tahun 2004 tentang Pemerintahan Daerah, telah membawa perubahan yang mendasar dalam sistem dan struktur Pemerintahan Daerah serta membawa dampak yang sangat luas bagi penyelenggaraan pemerintahan, perencanaan pembangunan, pengelolaan keuangan dan sistem penganggaran dalam menunjang penyelenggaraan pemerintahan di Daerah, khususnya pada tingkat Pemerintahan Desa. Untuk meningkatkan manajemen Pemerintahan Desa perlu dilakukan penataan administrasi agar lebih effektif dan effisien, penataan administrasi merupakan pencatatan data dan informasi dalam mendukung penyelenggaraan Pemerintahan Desa, maka perlu dilakukan langkah penyempurnaan terhadap pelaksanaan administrasi. Metode yang digunakan adalah metode ceramah, praktek langsung dengan file yang sudah diprogram tinggal diisi, tanya jawab, diskusi dan latihan untuk mengisi form yang sudah diprogram tinggal pengisian.

\section{Bahan dan Metode}

Metode yang digunakan adalah metode seminar, praktek langsung dengan file yang sudah diprogram tinggal diisi, tanya jawab, diskusi dan latihan untuk mengisi form yang sudah diprogram tinggal pengisian. 


\section{Jurnal Pengabdian Kepada Masyarakat BUGUH}

Dipublikasikan

Badan Pelaksana Kuliah Kerja Nyata Universitas Lampung

Sekretariat Badan Pelaksana Kuliah Kerja Nyata, Universitas Lampung J. Prof. Dr. Soemantri Brojonegoro No. 1, Bandar Lampung 35145.

Tahapan pelaksanaan adalah sebagai berikut:

1. Memberikan informasi kepada aparat desa bahwa akan diadakannya pelatihan penggunaan Microsoft office excel untuk penataan administrasi

2. Menyusun program dan teknis pelatihan

3. Menyiapkan alat dan bahan yang dibutuhkan untuk melakukan pelatihan

4. Pengadaan dan pembuatan modul untuk pelatihan

5. Melakukan seminar dan peraktek langsung dengan file yang sudah deprogram

6. Melakukan diskusi dan tanya jawab terkati materi yang disampaikan

7. Melakukan simulasi dan penerapan pada administrasi desa

8. Melakukan evaluasi

9. Melakukan kontrol berkelanjutan

Untuk mendukung realisasi penerapan metode yang ditawarkan diperlukan prosedur kerja yang jelas. Prosedur kerja itu akan dijelaskan melalui modul yang sudah dibuat dan dibagikan kepada objek pelatihan. Secara garis besar prosedur kerja tersebut adalah sebagai berikut:

1. Peserta bersiap didepan laptop yang disediakan

2. Peserta membuka Microsoft office excel

3. Menyiapkan berkas administrasi yang sudah diinisialisasi

4. Menginput berkas yang sudah diinisialisasi tersebut kedalam Microsoft excel

5. Menjelaskan teknik menginput berkas administrasi kedalam Microsoft office excel

6. Melakukan proses Tanya jawab dan evalusai

\section{Hasil dan Pembahasan}

Kegiatan ini tidak hanya sebatas pelatihan sekejap mata saja. Pada kegiatan ini akan dilakukan evaluasi bagaimana progres dan kinerja aparatur desa dalam penataan administrasi setelah dilakukannya pelatihan. Tidak hanya dilakukan evaluasi tetapi akan dimonitor bagaimana keberlanjutan program pelatihan ini. Jika sekiranya ada kekurangan maka akan dilakukan pelatihan tahap dua demi memastikan bahwa objek dapat memahami dan menjalankan program dengan baik.

Keahlian yang diperlukan dalam kegiatan pelatihan ini adalah keahlian dalam pengarsipan, keahlian dalam mengoprasikan Microsoft office excel dan keahlian dalam menyampaikan materi serta Tanya jawab yang dimana semua keahlian itu dimiliki oleh setiap anggota tim pengusul kegiatan Pelatihan Penggunaan Microsoft Office Excel Dalam Penataan Administrasi Desa Bagi Operator/Sekretaris Desa/Kampung/Kelurahan Se Kecamatan Kedondong Kabupaten Pesawaran sehingga diharapkan kegiatan ini akan dapat berjalan lancar.

Nama-nama anggota tim pengusul kegiatan Pelatihan Penggunaan Microsoft Office Excel Dalam Penataan Administrasi Desa Bagi Operator/Sekretaris Desa/Kampung/Kelurahan Se Kecamatan Kedondong Kabupaten Pesawaran adalah sebagai berikut:

1. Dr. Ir. Netti Herawati, sebagai ketua

2. Subian Saidi, S.Si., M.Si. sebagai anggota

3. Dr. Khoirin Nisa, M.Si. sebagai anggota

4. Drs. Eri Setiawan, M.Si. sebagai anggota

Setiap anggota memiliki kemampuan/keahlian seperti yang sudah dijelaskan pada sub-bab sebelumnya. 
Dipublikasikan

Badan Pelaksana Kuliah Kerja Nyata Universitas Lampung

Sekretariat Badan Pelaksana Kuliah Kerja Nyata, Universitas Lampung, J. Prof. Dr. Soemantri Brojonegoro No. 1, Bandar Lampung 35145.
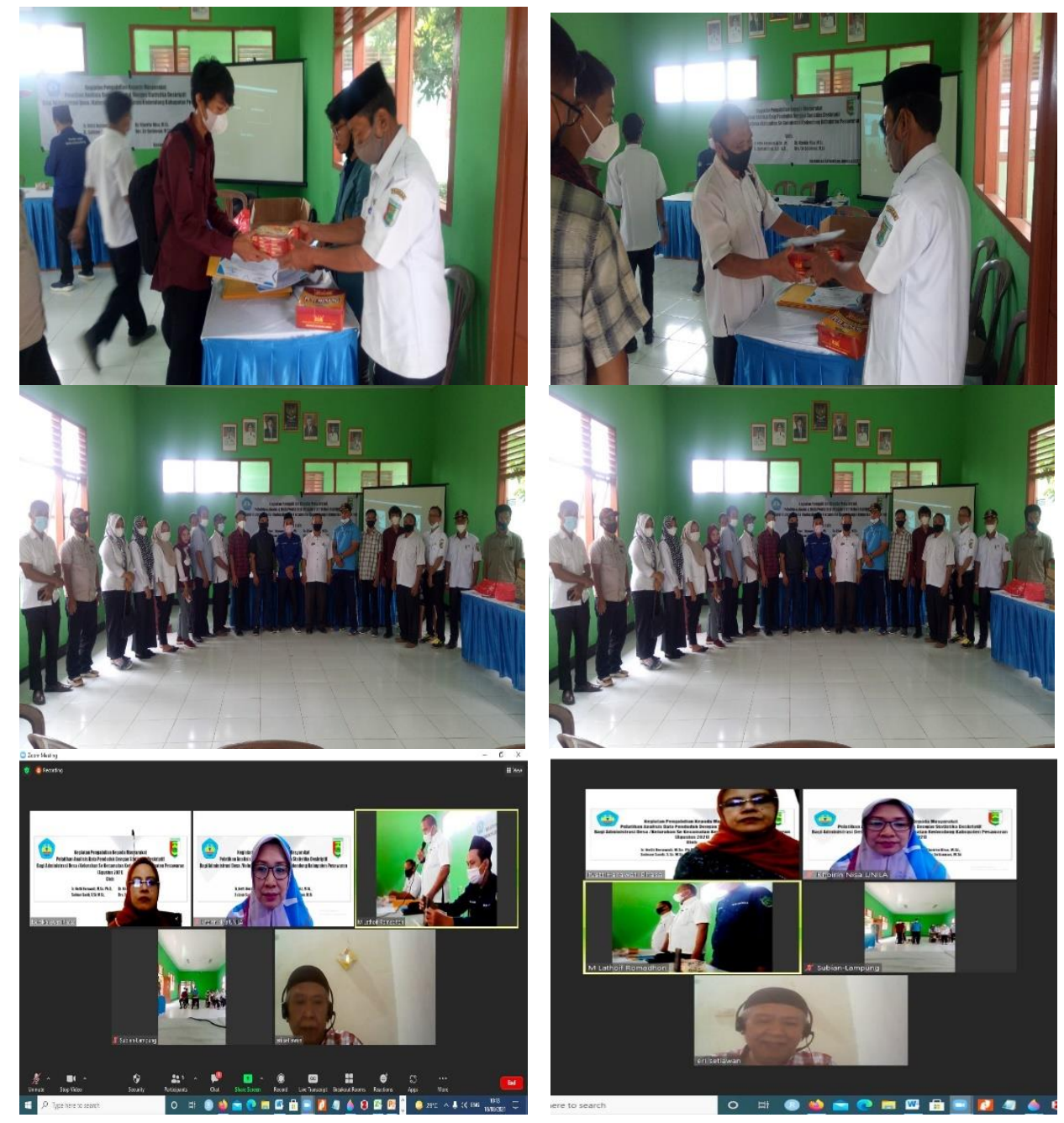

Gambar 1. Proses Pelatihan Microsoft Office Excel

Tabel 1. Keadaan awal dan keadaan akhir yang diharapkan dari peserta penyuluhan

No Keadaan Awal Perlakuan

Keadaan Akhir

1) Para operator/sekretaris desa belum terlalu memahami program yang praktis, efektif, dan efesien untuk pengarsipan administrasi
Melakukan pelatihan melalui applikasi Microsoft office excel dan membantu meningkatkan kemampuan para operator/sekretaris desa
Operator/sekretaris desa dapat men getahui cara bagaimana mengguna kan applikasi Microsoft office excel dalam melaksanakan tugas pengars ipan. 


\section{BUGUH}

Dipublikasikan

Badan Pelaksana Kuliah Kerja Nyata

Universitas Lampung

Sekretariat Badan Pelaksana Kuliah Kerja Nyata, Universitas Lampung,

J. Prof. Dr. Soemantri Brojonegoro No. 1, Bandar Lampung 35145.

1. Persiapan

Tabel 1. Persiapkan kegiatan

\begin{tabular}{|r|l|c|c|c|c|c|c|c|}
\hline No & \multicolumn{1}{|c|}{ Jenis Kegiatan } & \multicolumn{5}{|c|}{ Waktu Pelaksanaan Kegiatan } & \\
\hline 1 & Observasi Pustaka & 5 Hari & & & & & & \\
\hline 2 & Studi Pustaka & & 5 Hari & & & & & \\
\hline 3 & Pembuatan Proposal & & & 5 Hari & & & & \\
\hline 4 & $\begin{array}{l}\text { Melakukan Inventarisir / } \\
\text { Persiapan Pelatihan }\end{array}$ & & & & $\begin{array}{c}10 \\
\text { Hari }\end{array}$ & & & \\
\hline 5 & Pelaksanaan Pelatihan & & & & & $\begin{array}{c}05- \\
\text { Agust }\end{array}$ & & \\
\hline 6 & Laporan Draft & & & & & & 5 Hari & \\
\hline 7 & $\begin{array}{l}\text { Laporan Draft } \\
\text { (Perbaikan ) }\end{array}$ & & & & & & & 5 \\
Hari
\end{tabular}

1 Minggu $=5$ Hari

1 Hari $=5 \mathrm{Jam}$

1 Jam - 60 Menit

2. Pelaksanaan

Dalam pelaksanaan pelatihan disampaikan beberapa materi pokok tentang pengolahan data untuk statistika diskriptif diantaranya:

1. Pengenalan statistika dekriptif dan manajemen Data

2. Latihan angkah-langkah membuat table pada excel

3. Latihan perbandingan data perkolom

4. Latihanm mencari nilai mean (rata-rata), modus (nilai yang paling banyak muncul), median (nilai tengah), maksimum, minimum, jumlah data dan jumlah nilai dan persentase

5. Membuat Grafik Dengan Spark-Lines Object dan grafik dengan Chart Adapun jadwal pelatihan disajikan dalam tabel berikut.

Tabel 2. Pelaksanaan Kegiatan

\begin{tabular}{|r|l|l|l|}
\hline No. & \multicolumn{1}{|c|}{ Pukul } & \multicolumn{1}{|c|}{ Materi } & \multicolumn{1}{c|}{ Penyaji } \\
\hline 1 & $08.00-09.00$ & Persiapan dan Pembukaan & Mhs KKN \\
\hline 2 & $09.00-12.00$ & Materi I dan II & ES + NH + K + S + SS \\
\hline 3 & $12.00-13.00$ & Istirahat & Mhs KKN \\
\hline 4 & $13.00-15.00$ & Materi III & K + NH \\
\hline 5 & $15.00-17.00$ & Materi IV & ES + SS + S \\
\hline 6 & $17.00-17.30$ & Penutupan & Mhs KKN \\
\hline
\end{tabular}




\section{Jurnal Pengabdian Kepada Masyarakat BUCUH}

Dipublikasikan

Badan Pelaksana Kuliah Kerja Nyata Universitas Lampung

Sekretariat Badan Pelaksana Kuliah Kerja Nyata, Universitas Lampung, J. Prof. Dr. Soemantri Brojonegoro No. 1, Bandar Lampung 35145.

3. Alokasi Waktu

Tabel 3. Alokasi Waktu Kegiatan

\begin{tabular}{|c|c|c|}
\hline No & Kegiatan & Alokasi Waktu \\
\hline 1 & Persiapan & $3 \times 5 \times 5$ jam $=75,0 \mathrm{Jam}$ \\
\hline \multirow[t]{3}{*}{2} & Pelaksanaan & \\
\hline & a. Transfortasi (PP) & $=4,5 \mathrm{jam}$ \\
\hline & b. Pelaksanaan & $=9,5 \mathrm{Jam}$ \\
\hline \multirow[t]{2}{*}{3} & Laporan & $2 \times 5 \times 5 \mathrm{jam}=50,0 \mathrm{Jam}$ \\
\hline & Total & $=139,0 \mathrm{Jam}$ \\
\hline
\end{tabular}

\section{Kesimpulan}

Berdasarkan hasil pembahasan dari kegiatan yang telah dilakukan dapat disimpulkan bahwa:

Dalam kegiatan pelatihan penggunaan Microsoft office excel dalam penataan administrasi desa dibutuhkan kerjasama antar pihak-pihak terkait demi sukses dan lancarnya kegiatan ini. Pihak-pihak terkait yang ada dalam kegiatan ini adalah sebagai berikut:

1. Dosen Unila yang dalam hal ini hanya dosen yang mengusulkan kegiatan ini

2. Mitra/objek pelatihan yang dalam hal ini adalah operator/sekertasis desa beserta aparat yang ingin ikut berpartisipasi

3. Pihak-pihak lain yang secara tidak langsung terlibat dalam kegiatan ini

Demi kelancaran dan kesuksesan kegiatan ini diperlukan partisipasi mitra. Partisipasi yang dimaksud adalah kehadiran mereka dalam kegiratan, keaktifan mereka untuk bertanya, keterbukaan mitra dalam menerima materi yang disampaikan dan implementasi hasil pelatihan kedalam institusi. Partisipasi mitra juga dibutuhkan dalam menyiapkan peralatan dan tempat untuk melakukan pelatihan. Kegiatan ini tidak hanya sebatas pelatihan sekejap mata saja. Pada kegiatan ini akan dilakukan evaluasi bagaimana progres dan kinerja aparatur desa dalam penataan administrasi setelah dilakukannya pelatihan. Tidak hanya dilakukan evaluasi tetapi akan dimonitor bagaimana keberlanjutan program pelatihan ini. Jika sekiranya ada kekurangan maka akan dilakukan pelatihan tahap dua demi memastikan bahwa objek dapat memahami dan menjalankan program dengan baik.

\section{Ucapan Terima Kasih}

Puji syukur kepada Allah SWT yang senantiasa kami panjatkan karena hanya dengan rahmat dan hidayah-Nya kami dapat menyelesaikan pengabdian ini. Kami juga banyak mendapatkan dukungan dari berbagai pihak yang telah menyumbangkan pikiran, waktu, tenaga, dan sebagainya. Oleh karena itu, pada kesempatan yang baik ini kami mengucapkan terima kasih kepada:

a) LPPM Universitas Lampung

b) BPKKN Universitas Lampung

c) Kepala Desa Se Kec. Kendondong Kab. Pesawaran

d) Masyarakat Desa Kec. Kendondong Kab. Pesawaran 


\section{BUGUH}

Dipublikasikan

Badan Pelaksana Kuliah Kerja Nyata

Universitas Lampung

Sekretariat Badan Pelaksana Kuliah Kerja Nyata, Universitas Lampung,

J. Prof. Dr. Soemantri Brojonegoro No. 1, Bandar Lampung 35145.

\section{Daftar Pustaka}

Agung Kurniawan. (2005). Transformasi Pelayanan Publik. Yogyakarta: Pembaharuan

Anggorowati, A., dkk. (2016). Pelatihan Pengelolaan Arsip Dinamis Bagi Aparat Desa Di Kantor Desa Tambaksorga Kecamatan Sumbang Kabupaten Banyumas. Prosiding Seminar Nasional dan Call for Papers "Pengembangan Sumber Daya Perdesaan dan Kearifan Lokal Berkelanjutan VI”.

Badan Pusat Statistik Kabupaten Pesawaran. (2020). Kecamatan Kedondong Dalam Angka. Pesawaran.

Hariyono, P. (2007). Sosiologi Kota untuk Arsitek, Bumi Aksara, Jakarta.

Higau, C. B. H. (2015). Pelaksanaan Administrasi Pemerintahan Desa Dalam Meningkatkan Pelayanan Masyarakat Di Desa Matalibaq Kecamatan Long Hubung Kabupaten Mahakam Ulu. eJournal Ilmu Pemerintahan. 3(3); 1448-1459.

Liang Gie, T. (1997). Kamus Administrasi, Jakarta: PT. Gunung Agung.

Pasolong, H. (2007). Teori Administrasi Publik. Bandung: Alfabeta

Sinambela, Poltak Lijan. (2006). Reformasi Pelayanan Publik, Jakarta, Bumi Aksara

Syafiie, I. K. (2002). Sistem Pemerintahan Indonesia, PT. Rineka Cipta, Jakarta

Undang-Undang Nomor 32 Tahun 2004 tentang Pemerintahan Daerah

Undang-Undang Nomor 6 Tahun 2014 tentang Desa

Widjaja, AW. (2002). Pemerintahan Desa dan Administrasi Desa, PT. Raja Grafindo Persada, Jakarta 